\title{
On the Possibility of Reducing Friction due to Relaminarization of the Flow in the Pipe
}

\author{
A.I. Reshmin, V.V. Trifonov, V.G. Lushchik, M.S. Makarova \\ Institute of Mechanics, Lomonosov Moscow State University, \\ Moscow, 119192, Russia \\ mariia.makarova@gmail.com
}

\begin{abstract}
Using the differential turbulence model, a numerical study of the possibility of relaminarization of the flow in a pipe is carried out for three variants of input devices with different velocity profiles and small-scale turbulence. The most promising is the experimentally investigated option with the organization of a two-zone flow with a slowed flow in the central region of the pipe and accelerated flow in the wall region. In this variant, the Reynolds number of relaminarization $\mathrm{Re}^{*}$ is 16000 . It is shown that a further increase in the number of $\mathrm{Re}^{*}$ can be obtained by decreasing the turbulence intensity and turbulence scale at the inlet.
\end{abstract}

Key words: pipe, input device, relaminarization, differential turbulence model 


\title{
О возможности снижения трения за счет ламинаризации течения в трубе
}

\author{
А.И. Решмин, В.В. Трифонов, В.Г. Лущик, М.С. Макарова \\ НИИ механики МГУ имени М.В. Ломоносова, \\ Россия, Москва, 119192, Мичуринский пр., 1 \\ mariia.makarova@gmail.com
}

\begin{abstract}
Аннотация
С использованием дифференциальной модели турбулентности проведено численное исследование возможности реламинаризации течения в трубе для трех вариантов входных устройств с различными профилями скорости и мелкомасштабной турбулентностью. Наиболее перспективным оказался экспериментально исследованный вариант с организацией двухзонного течения с замедленным потоком в центральной области трубы и ускоренным в пристеночной области. В этом варианте получено число Рейнольдса реламинаризации $\mathrm{Re}^{*}=16000$. Показано, что дальнейшее повышение числа $\mathrm{Re}^{*}$ может быть получены при уменьшении интенсивности и масштаба турбулентности на входе.
\end{abstract}

Ключевые слова: труба, входное устройство, реламинаризация, дифференциальная модель турбулентности

\section{1. Введение}

Потери давления из-за трения при турбулентном режиме течения связаны с ростом потребления энергии на прокачку газа или жидкости по трубам и, как следствие, с возрастанием эксплуатационных расходов. В случае ламинаризации (реламинаризации) течения, т.е. при переходе с турбулентного режима течения к ламинарному, потери из-за трения могут быть существенно снижены. Так, например, для течения с числом Рейнольдса 25000 эти потери будут уменьшены на порядок.

В [1] представлен обзор ряда способов реламинаризации турбулентного течения в трубах. В частности, отмечено, что для управления турбулентным потоком использовались сетки и хонейкомбы, при помощи которых уровень турбулентности на входе можно уменьшить, но реламинаризации течения достичь не удалось. Следует отметить, что в [2] упомянуты работы по исследованию перехода к турбулентности в затопленных и спутных струях и в трубе, в которых также использовались хонейкомбы для формирования течений с заданным входным профилем скорости и турбулентностью малой интенсивности и масштаба.

В экспериментах [1] использовалось два способа формирования профиля скорости на входе в участок реламинаризации турбулентного потока. Первый состоял в установке в трубу кольцевой вставки с перфорированной решеткой, создающей гидравлическое сопротивление. Проходя через кольцевую вставку с решеткой, поток тормозится относительно спутного потока, проходящего через кольцевой зазор между вставкой и трубой. Второй способ состоял в организации ввода спутного потока с большей скоростью через кольцевой зазор у стенки трубы. В [1] первым способом получена реламинаризация турбулентного течения при числе Рейнольдса $\mathrm{Re}^{*}=3800$, при втором способе - при $\mathrm{Re}^{*}=6000$. Увеличение числа $\mathrm{Re}^{*}$ при втором способе управления потоком можно объяснить более низким уровнем турбулентности в центральном потоке по сравнению с уровнем турбулентности, генерируемым решеткой в первом способе. Анализ полученных в [1] результатов позволяет сде- 
лать вывод, что для достижения более высокого числа Рейнольдса, при котором наступает реламинаризация, необходимо сформировать поток не только с заданным профилем скорости, но и с низким уровнем турбулентности.

В [2] экспериментально и численно исследован новый класс течений с неоднородными (трапецевидным, U-образным и $\Lambda$-образным) профилями скорости и мелкомасштабной турбулентностью на входе, сформированными входными устройствами с переменным гидравлическим сопротивлением типа хонейкомбов, размер ячейки которых много меньше толщины слоя с градиентом скорости. Для расчета неравновесных турбулентных течений, представленных в [2], использовалась дифференциальная модель турбулентности [3] с уравнениями переноса для трех параметров: энергии турбулентности $E=0.5 \sum<u_{i}^{\prime 2}>$, напряжения сдвига $\tau=-\left\langle u^{\prime} v^{\prime}\right\rangle$ и параметра $\omega=E / L^{2}$, содержащего масштаб турбулентности $L$. Все константы в уравнениях переноса для характеристик турбулентности были определены из анализа трех эталонных экспериментов, имеющих высокую достоверность: течения за решеткой без градиента скорости, течения за решеткой с постоянным градиентом скорости и развитого турбулентного течения в канале [3]. Анализ этих течений позволил получить значения констант до численного решения уравнений. При расчетах течений, отличных от тех, из анализа которых определялись константы, значения констант не изменялись и эмпирические функции от параметров задачи не вводились.

Численное исследование реламинаризации турбулентного течения в трубе, результаты которого представлены ниже, проведено с использованием уравнений неразрывности и движения в приближении узкого канала и трехпараметрической дифференциальной модели турбулентности [3-5].

\section{2. Результаты численного исследования}

\section{1. Расчет течений для условий эксперимента [1]}

Для расчета турбулентного течения в трубе использованы уравнения неразрывности и движения в приближении узкого канала, где продольный градиент давления определяется в процессе решения из условий сохранения расхода в трубе.

Для определения турбулентного трения $\rho \tau=-\rho\left\langle u^{\prime} v^{\prime}\right\rangle$, входящего в уравнение движения, использовалась трехпараметрическая дифференциальная модель турбулентности [3].

Граничные условия на стенке трубы диаметром $D$, на оси симметрии и на входе в трубу

$$
\begin{gathered}
u=0, v=0, \quad E=\frac{\partial E}{\partial r}=\tau=0 \quad\left(r=\frac{D}{2}\right) \\
\frac{\partial u}{\partial r}=v=0, \quad \frac{\partial E}{\partial r}=\frac{\partial \omega}{\partial r}=\tau=0 \quad(r=0) \\
p=\text { const }, u=u(r), \quad E=E(r), L=L(r), \quad \tau=0 \quad(x=0)
\end{gathered}
$$

Система уравнений неразрывности, движения и модели турбулентности с граничными условиями, решалась численно методом прогонки с итерациями. Расчеты проводились на неравномерной сетке. Шаг по радиусу трубы вблизи стенки был малым. Шаг по продольной координате был также достаточно мал в сечениях, близких к входному сечению, и увеличивался по мере продвижения вниз по потоку, что позволило проводить расчеты даже при достаточно малом уровне турбулентности на входе в трубу.

Результаты численного исследования реламинаризации турбулентного течения, как будет показано ниже, существенным образом зависят от условий на входе в участок реламинаризации: профиля скорости и характеристик турбулентности. 
Расчетная схема представлена на рис. 1. Профиль скорости на входе в участок реламинаризации был принят соответствующим профилю скорости при первом способе формирования потока работы [1]. В трубе внутренним диаметром $D=2 R=30$ мм было организовано два спутных потока: центральный поток (индекс “2”), выходящий из кольцевой вставки внутренним диаметром $d_{2}=2 r_{2}=26$ мм со среднерасходной скоростью $U_{2}$, и кольцевой пристеночный поток (индекс “1”) в зазоре шириной 1 мм между кольцевой вставкой наружном диаметром $d_{1}=2 r_{1}=28$ мм и трубой со среднерасходной скоростью $U_{1}$. Отношение скоростей спутных потоков было принято $U_{1} / U_{2}=1.67$, что соответствует отношению расходов потоков $Q_{1} / Q_{2} \approx 0.3$.

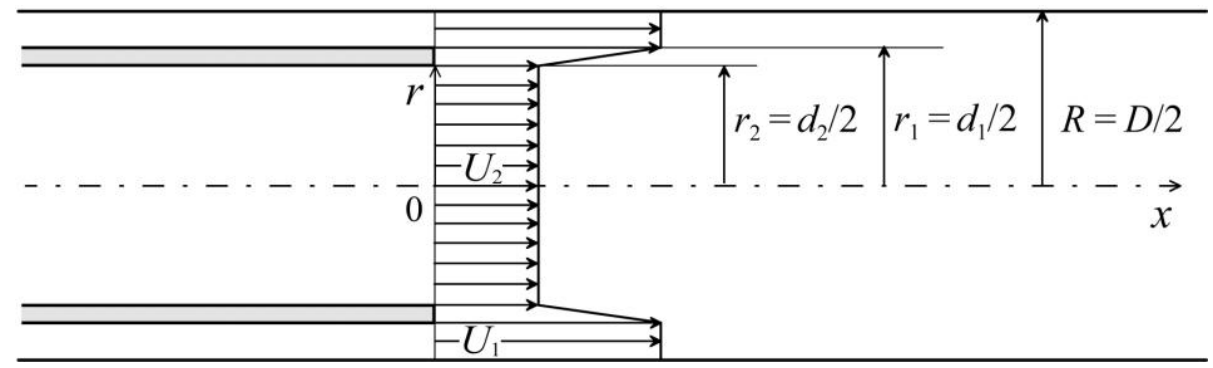

Рис. 1. Расчетная схема

Что касается характеристик турбулентности на входе в участок реламинаризации, то они могут быть установлены лишь приближенно. Так, для центрального потока, где турбулентность генерируется решеткой с отверстиями диаметром $d_{3}=3.3$ мм, интенсивность турбулентности непосредственно за решеткой будет достаточно высокой. Однако на длине вставки $L_{t}=200$ мм $\left(L_{t} / d_{2} \approx 7\right)$ интенсивность турбулентности снизится. В расчетах на входе в участок реламинаризации (индекс “0”) в центральном потоке была принята величина интенсивности турбулентности $e_{02}=\sqrt{E_{02}} / U_{2}=0.05\left(\sqrt{E_{02}} / U=0.044\right)$ и на расстоянии $z=x / D=2$ от входа снизится еще до величины $e_{c l}=\sqrt{E_{c l}} / U=0.036$ (см. рис. 3) на оси трубы (индекс “cl”), что близко к величине $2 u^{\prime} / U$, полученной на том же расстоянии от входа в эксперименте [1]. Масштаб турбулентности на входе $L_{02}$ в центральном потоке был принят примерно равным диаметру отверстий перфорации решетки, так что относительная величина масштаба составила $l_{02}=L_{02} / R=0.2$.

Оценки интенсивности и масштаба турбулентности для спутного потока позволили установить следующее. Поскольку поток в зазоре шириной 1 мм между вставкой и трубой близок к ламинарному, то возмущения в нем будут минимальными. Однако наличие кромки кольцевой вставки толщиной 1 мм приводит к турбулизации спутного потока с масштабом турбулентности порядка толщины кромки. В расчетах для спутного потока были приняты следующие входные величины интенсивности $e_{01}=\sqrt{E_{01}} / U_{1}=0.007 \quad\left(\sqrt{E_{01}} / U=0.01\right)$ и масштаба турбулентности $l_{01}=L_{01} / R=0.07$.

Напряжение сдвига в обоих потоках на входе было принято $\tau=-\left\langle u^{\prime} v^{\prime}\right\rangle=0$. Профиль скорости в спутных потоках на входе был принят однородным с линейным изменением на кромке кольцевой вставки (см. рис. 1).

Расчеты выполнены для чисел Рейнольдса $\operatorname{Re}=D \cdot U / v$, приведенных в [1], которые определены по диаметру трубы $D$, среднерасходной скорости потока $U$ и кинематической вязкости воздуха $v$.

Результаты численного исследования для чисел Рейнольдса $\operatorname{Re}=3800$ и $\operatorname{Re}=4500$ в первом способе реламинаризации работы [1] представлены на рис. 2-6. На рис. 2. приведено изменение по длине участка реламинаризации $z=x / D$ относительной скорости потока на оси трубы $u_{c l} / U$. Как видно, реламинаризация, как и в эксперименте [1], достигается на длине $z=x / D=100$ при числе Рейнольдса $\mathrm{Re}=3800$, что подтверждается величиной $u_{c l} / U=1.8$, близкой к значению $u_{e l} / U=2$ для ламинарного режима течения. Изменение 
интенсивности турбулентности на оси трубы $e_{c l}=\sqrt{E_{c l}} / U$ (рис. 3), стремящейся к нулю, и коэффициента сопротивления $\xi=(\rho v \partial u / \partial r)_{w}$ (рис. 4), близкого к величине $\xi=64 / \operatorname{Re}$ для ламинарного режима течения, также подтверждают достижения реламинаризации при числе Рейнольдса $\operatorname{Re}=3800$. Для числа $\operatorname{Re}=4500$ при тех же входных условиях реламинаризации, как и в эксперименте [1], получено не было (см. рис. 2-4).

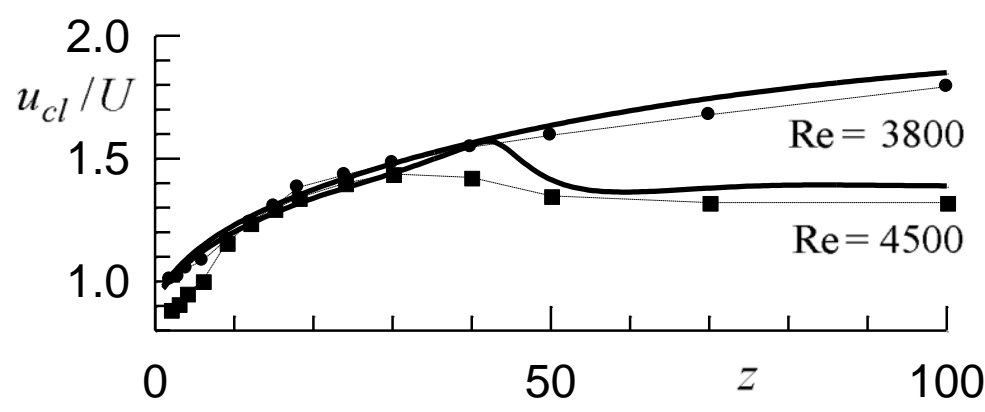

Рис. 2. Изменение по длине участка реламинаризации $z=x / D$ относительной скорости потока на оси трубы $u_{c l} / U$ для двух чисел Рейнольдса: точки - эксперимент [1], линии - расчет

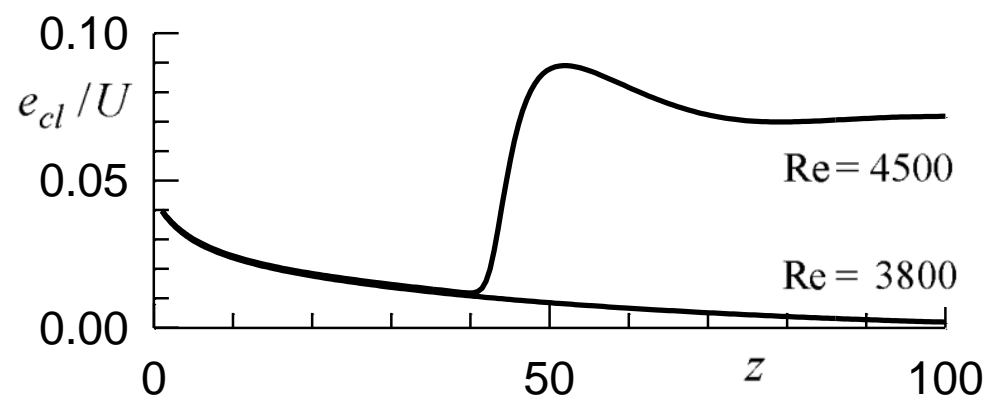

Рис. 3. Изменение интенсивности турбулентности на оси трубы $e_{c l}=\sqrt{E_{c l}} / U$ по длине $z=x / D$ для двух чисел Рейнольдса

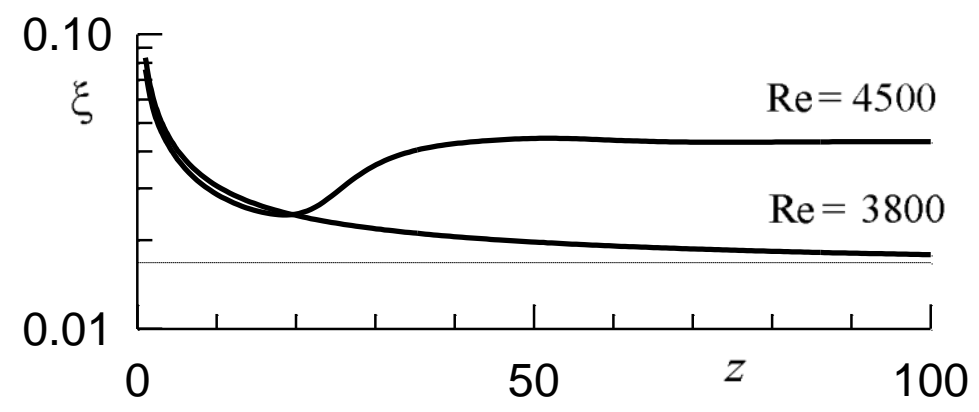

Рис. 4. Изменение по длине $z=x / D$ коэффициента сопротивления $\xi=(\rho v \partial u / \partial r)_{w}$ (штриховая линия $\xi=64 / \operatorname{Re}$ для ламинарного режима течения) для двух чисел Рейнольдса

Профиль скорости в случае реламинаризации течения $(\mathrm{Re}=3800)$ при $z=100$ близок к профилю Пуазейля. Для $\operatorname{Re}=4500$, когда реламинаризация не наступает, профиль скорости при $z=100$ близок к профилю скорости для турбулентного течения В случае реламинаризации течения $(\operatorname{Re}=3800)$ наиболее резкое снижение интенсивности турбулентности, как и в эксперименте [1], имеет место в области вблизи стенки трубы. Согласно [1] это означает подавление генерации турбулентности в пристеночной области, где она в отсутствие реламинаризации максимальна.

На рис. 5 приведены расчетное изменение максимальной величины генерации турбулентности $P_{m}=-(\rho \tau \partial u / \partial r)_{m}$ (рис. 5, $\left.a\right)$ и координата максимума генерации $r_{m} / R$ (рис. 5, б) 
по длине $z=x / D$ для двух чисел Рейнольдса. Полученные результаты свидетельствуют о том, что в случае реламинаризации $(\operatorname{Re}=3800)$ генерация турбулентности подавляется и максимум ее смещается от стенки к оси трубы. В случае отсутствия реламинаризации $(\operatorname{Re}=4500)$ максимум генерации турбулентности возрастает с выходом на режим развитого турбулентного течения при $z=100$ и положение максимума генерации $r_{m} / R$ остается в пристеночной области. Эти результаты подтверждают сделанное в [1] предположение о том, что основополагающий физический механизм реламинаризации связан с ослаблением цикла производства пристеночной турбулентности.

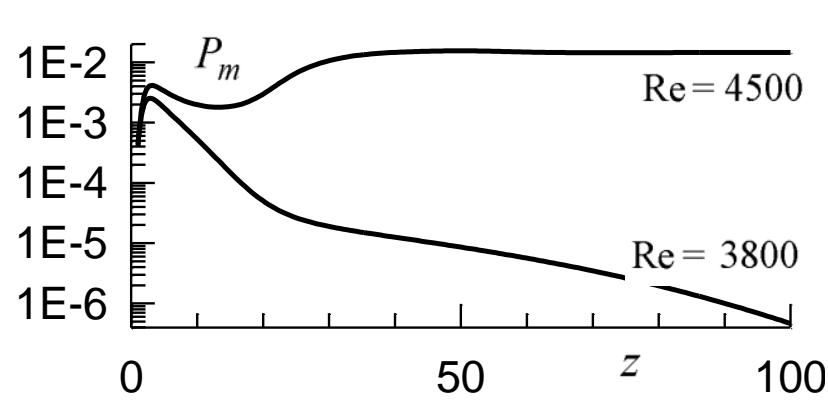

$a$

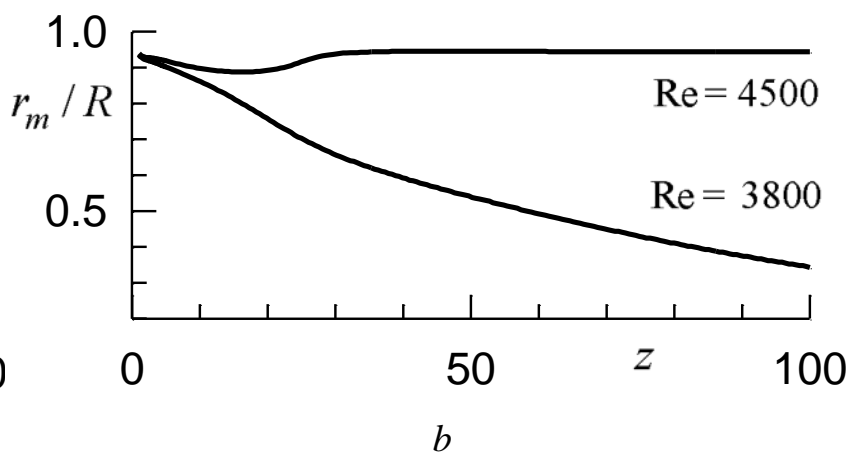

Рис. 5. Изменение максимальной величины генерации турбулентности $P_{m}=-(\rho \tau \partial u / \partial r)_{m}(a)$ и координата максимума генерации $r_{m} / R(\sigma)$ по длине $z=x / D$ для двух чисел Рейнольдса

Таким образом, приведенные на рис. 2-5 результаты численного исследования, в частности профили скорости и интенсивности турбулентности, ввиду недостаточной информации по характеристикам турбулентности на входе в участок реламинаризации, лишь качественно соответствуют экспериментальным данным [1]. Тем не менее полученные результаты подтверждают возможность реламинаризации течения с замедленным потоком в центральной области трубы и ускоренным - в пристеночной области. Полученное в расчете число Рейнольдса реламинаризации $\mathrm{Re}=3800$ соответствует экспериментальному значению, полученному в [1].

Такое невысокое значение числа Рейнольдса реламинаризации объясняется достаточно высокой интенсивностью турбулентности в центральной области, обусловленной постановкой турбулизирующей решетки для организации замедленного потока.

Уменьшение интенсивности турбулентности на входе в центральной области при отсутствии турбулизирующей решетки во втором способе организации течения в работе [1] позволило повысить число Рейнольдса реламинаризации течения до величины $R e=6000$.
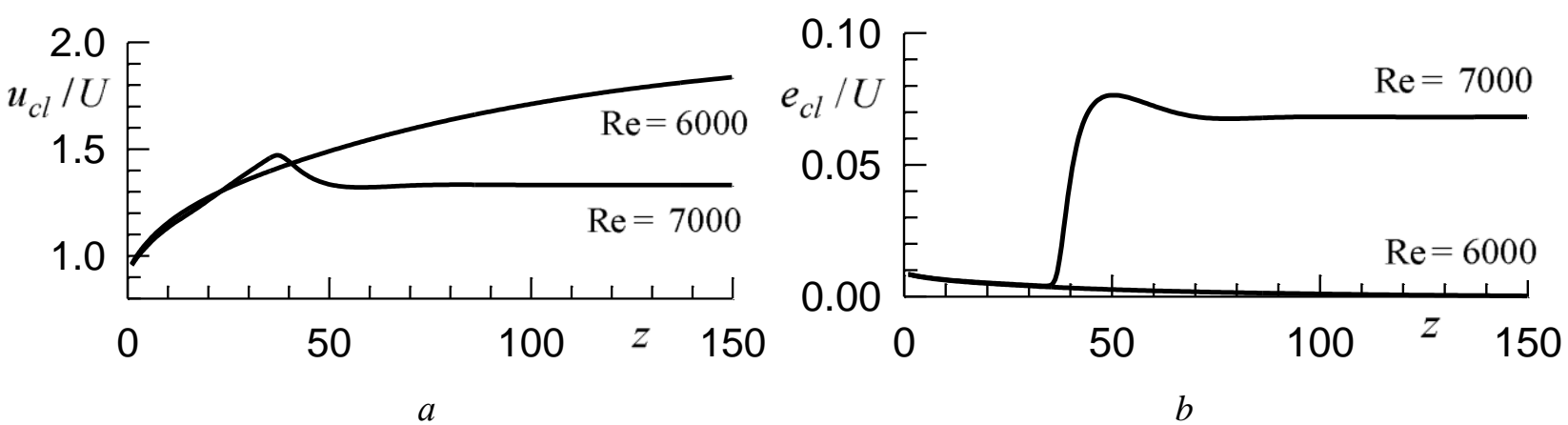

Рис. 6. Изменение по длине участка реламинаризации $z=x / D$ относительной скорости потока $u_{c l} / U(a)$ и интенсивности турбулентности $e_{c l}=\sqrt{E_{c l}} / U(\sigma)$ на оси трубы для двух чисел Рейнольдса

Численное исследование было проведено при двух числах Рейнольдса: $\operatorname{Re}=6000$ и $\operatorname{Re}=7000$ для следующих входных условий: $U_{1} / U_{2}=1.67, e_{02}=\sqrt{E_{02}} / U=0.01, L_{02} / R=0.2$, 
$e_{01}=\sqrt{E_{01}} / U=0.01, L_{01} / R=0.1$. При числе $\operatorname{Re}=6000$, как и в эксперименте [1], получена реламинаризация течения, при $\mathrm{Re}=7000$ реламинаризация на длине $z=100$ достигнута не была.

На рис. 6 в качестве иллюстрации сказанного для двух чисел Рейнольдса $\mathrm{Re}=6000$ и $\mathrm{Re}=7000$ представлено изменение по длине участка реламинаризации $z=x / D$ относительной скорости потока $u_{c l} / U(a)$ и интенсивности турбулентности $e_{c l}=\sqrt{E_{c l}} / U$ (б) на оси трубы.

\section{2. Влияние профиля скорости на реламинаризацию при низком уровне входных возмущений}

Как отмечено во введении, анализ полученных в [1] результатов экспериментального исследования позволяет сделать вывод, что для достижения более высокого числа Рейнольдса реламинаризации, необходимо сформировать поток не только с заданным профилем скорости, но и с низким уровнем турбулентности. В этой связи представляет интерес исследовать как влияет входной профиль скорости на возможность реламинаризации при низком уровне характеристик турбулентности, генерируемым входным устройством.

При проведении численного исследования рассмотрено три варианта входных устройств [6]:

- $\quad$ вариант 1 с $U$-образным профилем скорости (см. рис. 1), аналогичным рассмотренному в эксперименте [1], с параметрами $r_{1} / R=0.9, r_{2} / R=0.87, U_{1} / U_{2}=1.5$;

- $\quad$ вариант 2 с $\Lambda$-образным профилем скорости, с параметрами $r_{1} / R=0.9, r_{2} / R=0.87$, $U_{1} / U_{2}=0.6$

- $\quad$ вариант 3 с параболическим профилем скорости.

Во всех трех вариантах характеристики турбулентности на входе были одинаковыми и приняты следующими: интенсивность турбулентности, определенная по местной скорости $u, e_{0}=\sqrt{E_{0}} / u=0.01$, масштаб турбулентности $L_{0} / R=0.05$.

Отметим, что выбор варианта 3 входного устройства с параболическим профилем скорости на входе, реализованный с использованием хонейкомба в работе [7], обусловлен тем обстоятельством, что профиль скорости при достижении реламинаризации будет стремиться к параболическому, т.е. остается близким к входному профилю скорости. При этом коэффициент сопротивления $\xi$ на всей длине для варианта 3 наименьший из величин $\xi$ для трех рассмотренных вариантов входных устройств и близок к ламинарному значению $\xi=64 / \mathrm{Re}$.

На рис.7 представлены зависимости от числа Рейнольдса $\mathrm{Re}=D U / v$ величин $e_{c l}=\sqrt{E_{c l}} / U(a)$ и $\xi(б)$ для трех вариантов входных устройств.

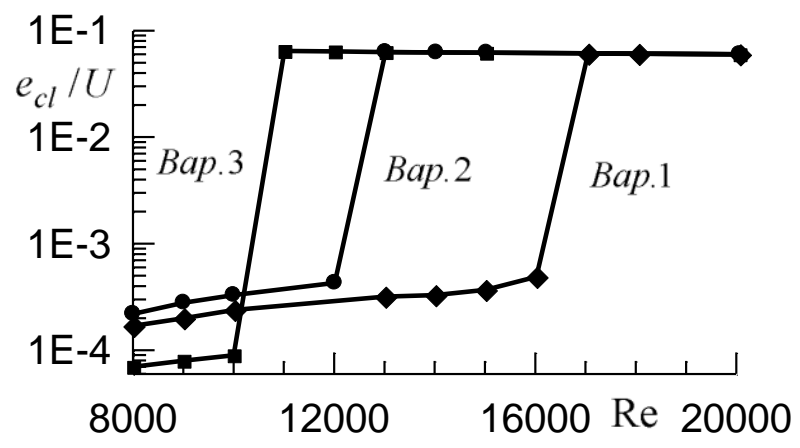

$a$

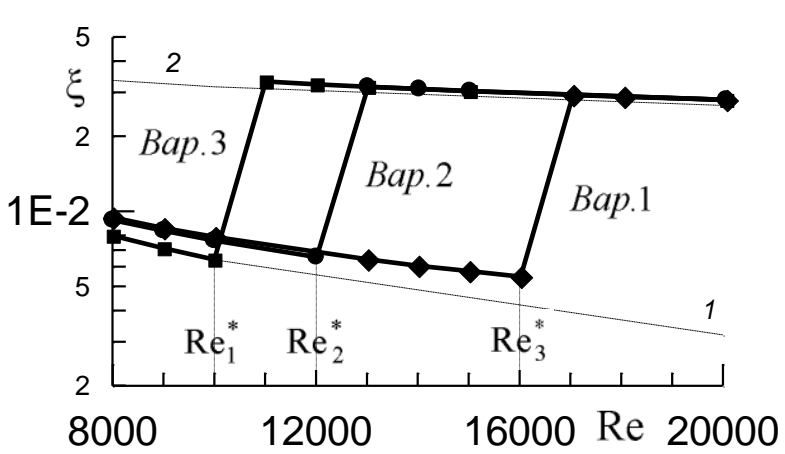

$b$

Рис. 7. Зависимости от числа Рейнольдса $\operatorname{Re}=D U / v$ величин интенсивности турбулентности $e_{c l}=\sqrt{E_{c l}} / U(a)$ на оси трубы и коэффициента сопротивления $\xi(б)$ для трех вариантов входных устройств (Bap. 1, Bap. 2, Bap. 3 - линии и точки); линия 1 на рис. $7, b-\xi=64 / \operatorname{Re}$; линия 2 на рис. $7, b-\xi=0.316 / \mathrm{Re}^{1 / 4}$ 
Достижение режима реламинаризации в расчетах определялось, как и в [1], по изменению по длине трубы интенсивности турбулентности $e_{c l}=\sqrt{E_{c l}} / U$ (рис. 7,a) на оси трубы, а также по изменению коэффициента сопротивления $\xi$ (рис. 7, б).

В расчетах, проведенных с шагом по числу Рейнольдса $\mathrm{d} R \mathrm{Re}=1000$, получено, что реламинаризация наступает для варианта входного устройства 1 в диапазоне чисел Рейнольдca $\operatorname{Re}=(16 \div 17) \times 10^{3}$, для варианта $2-$ в диапазоне чисел Рейнольдса $\operatorname{Re}=(12 \div 13) \times 10^{3}$, для варианта 3 - в диапазоне чисел Рейнольдса $\operatorname{Re}=(10 \div 11) \times 10^{3}$.

Во всех трех вариантах, как указано выше, характеристики турбулентности на входе были одинаковыми $\left(e_{0}=\sqrt{E_{0}} / u=0.01, L_{0} / R=0.05\right)$. Для вариантов расчета 1 и 2 с двухзонной организацией течения представляет интерес исследовать влияние различных входных условий в пристенном потоке на число Рейнольдса реламинаризации течения.

На рис. 8 представлены зависимости числа Рейнольдса реламинаризации $\mathrm{Re}^{*}$ от входных величин интенсивности турбулентности $e_{02}=\sqrt{E_{02}} / U_{2},\left(L_{02} / R=0.05\right)$ (a) и относительного масштаба турбулентности $l_{02}=L_{02} / R\left(e_{02}=\sqrt{E_{02}} / U_{2}=0.01\right)$ (б) в пристеночном потоке для вариантов 1 и 2 входных устройств.

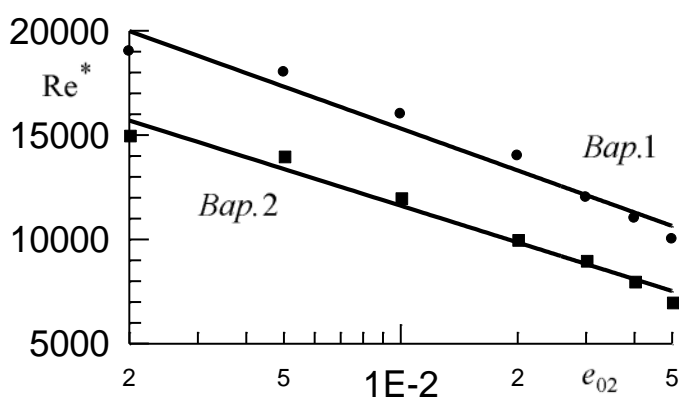

$a$

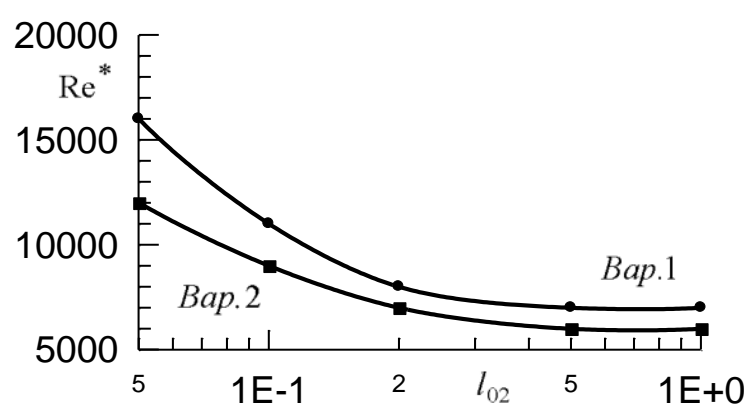

$b$

Рис. 8. Зависимость числа Рейнольдса реламинаризации $\mathrm{Re}^{*}$ от интенсивности турбулентности $e_{02}=\sqrt{E_{02}} / U_{2}(a)$ и масштаба турбулентности $l_{02}=L_{02} / R($ б) в пристеночном потоке для двух вариантов входных устройств (Bap. 1, Bap. 2 - линии и точки)

Как видно из рис. $8, a$, снижение входной интенсивности турбулентности $e_{02}$ в пристенном потоке существенно повышает число Рейнольдса реламинаризации Re*. Это повышение величины $\mathrm{Re}^{*}$ в большей степени относится к варианту 1 с увеличенной скоростью пристеночного потока. Что касается влияния входного масштаба турбулентности $l_{02}$ (рис. 8, б), то влияние его на величину $\mathrm{Re}^{*}$ существенно для малых масштабов $\left(l_{02}<0.2\right)$. Для крупномасштабной входной турбулентности величина $\operatorname{Re}^{*}$ практически не зависит от $l_{02}$.

\section{3. Заключение}

С использованием трехпараметрической дифференциальной модели турбулентности проведен расчет течений, для которых получены экспериментальные данные [1] по реламинаризации турбулентного течения в трубе. Получено удовлетворительное согласие результатов расчета с экспериментальными данными по профилям скорости, интенсивности турбулентности и числам Рейнольдса реламинаризации, что свидетельствует об адекватности используемой в расчетах модели турбулентности. Полученные результаты расчета подтвердили возможность реламинаризации течения с замедленным потоком в центральной области трубы и ускоренным в пристеночной области.

Проведенное численное исследование для трех вариантов входных устройств с неоднородным профилем скорости и мелкомасштабной турбулентностью на входе показало возможность достижения реламинаризации течения в трубах при числах Рейнольдса $\operatorname{Re}>10000$. Во всех трех вариантах характеристики турбулентности на входе были одинако- 
выми и приняты следующими: интенсивность турбулентности, определенная по местной скорости $u, e_{0}=\sqrt{E_{0}} / u=0.01$, масштаб турбулентности $L_{0} / R=0.05$.

Из трех рассмотренных вариантов входных устройств наиболее перспективным оказался вариант 1, экспериментально исследованный в работе [1] с организацией двухзонного течения с замедленным потоком в центральной области трубы и ускоренным в пристеночной области. В этом варианте получено число Рейнольдса реламинаризации $\mathrm{Re}^{*}=16000$. Для варианта 2 с ускоренным потоком в центральной области трубы и замедленным в пристеночной области получено меньшее число Рейнольдса реламинаризации $\operatorname{Re}^{*}=12000$. Для варианта 3 с параболическим профилем скорости на входе получено наименьшее из тех вариантов число Рейнольдса реламинаризации $\mathrm{Re}^{*}=10000$.

Показано, что дальнейшее повышение числа Рейнольдса реламинаризации может быть получено при уменьшении интенсивности и масштаба турбулентности на входе. Так, например, для варианта 1 входного устройства снижение входной интенсивности турбулентности с $e_{0}=1 \%$ до $e_{0}=0.5 \%$ при величине масштаба турбулентности $l_{0}=0.05$ повышает величину $\mathrm{Re}^{*}$ с 16000 до 18000.

Работа выполнена в рамках исследований, частично финансируемых гос. бюджетом (АААА-A16-116021110203-6, АААА-А16-116021110200-5), РФФИ (№ 17-08-00115) и Советом по грантам Президента РФ (№ СП-3993.2018.1).

\section{Литература}

1. Kuhnen J., Scarselli D., Schaner M., Hof B. Relaminarization by Steady Modification of the Streamwise Velocity Profile in a Pipe // Flow Turbulence Combust. 2018. No 100. Pp. 919-943.

2. Лущик В.Г., Павельев А.А., Якубенко А.Е. Итоги науки и техники. Сер. Механика жидкости и газа. М.: ВИНИТИ. 1988. Т. 22. С. 3-61.

3. Лущик В.Г., Павельев А.А., Якубенко А.Е. Трехпараметрическая модель сдвиговой турбулентности // Изв. АН СССР. МЖГ. 1978. № 3. С. 13-25.

4. Лущик В.Г., Макарова М.С., Решмин А.И. Ламинаризация потока при течении в плоском канале с конфузором // Изв. РАН. МЖГ, 2019. №1. С. 68-77.

5. Макарова М.С., Лущик В.Г., Решмин А.И. Исследование условий возникновения полной реламинаризации течения в плоских конфузорных каналах. В сб.: Современные проблемы механики и математики // Научные слушания, посвященные 110 -летию со дня рождения С.А. Христиановича. Сборник материалов.2018. С. 66-68.

6. Лущик В.Г., Макарова М.С., Решмин А.И. Способы управления турбулентным потоком при ламинаризации течения в трубе // XII Всероссийский съезд по фундаментальным проблемам теоретической и прикладной механики. Аннотации докладов Изд-во: РИЦ БашГУ Уфа, 2019. C. 102.

7. Коляда В.В., Павельев А.А. Влияние профиля скорости на входе в круглую трубу на переход к турбулентности // Изв. АН СССР. МЖГ. 1986. № 4. С. 166-169.

Статья поступила в редакцию 17 октября 2019 г. 